state," says Al Medvitz, UC Davis lecturer and Solano County grower.

Women growers. The increase in female farmers has also occurred primarily on small farms, Blank says, either with wives taking over when their husbands die or obtain off-farm jobs, or with women starting their own specialty or "niche" operations.

Specialty farming often appeals to women because "they can go anywhere in the state and grow something," says Jeri Hansen, vice president of California Women in Agriculture (CWA), a trade association with 3,500 members and 27 chapters.

Janet Pauli, operator of Pauli Ranch, oversees crews of between 25 and 80 workers on 450 acres of wine grapes and 60 acres of pears in Mendocino County. "I may get more respect [from mostly male crews] automatically because of being female," Pauli says.

Farming has also allowed Pauli to seamlessly integrate her work and family lives. "It's wonderful to work here and be with my children," says Pauli, who has two sons with husband Bill, president of the California Farm Bureau Federation. "The children are raised in it. Day care has never been a problem. Some women find it much easier to raise kids on the farm." - Janet Byron

\title{
Grandparents become primary parents
}

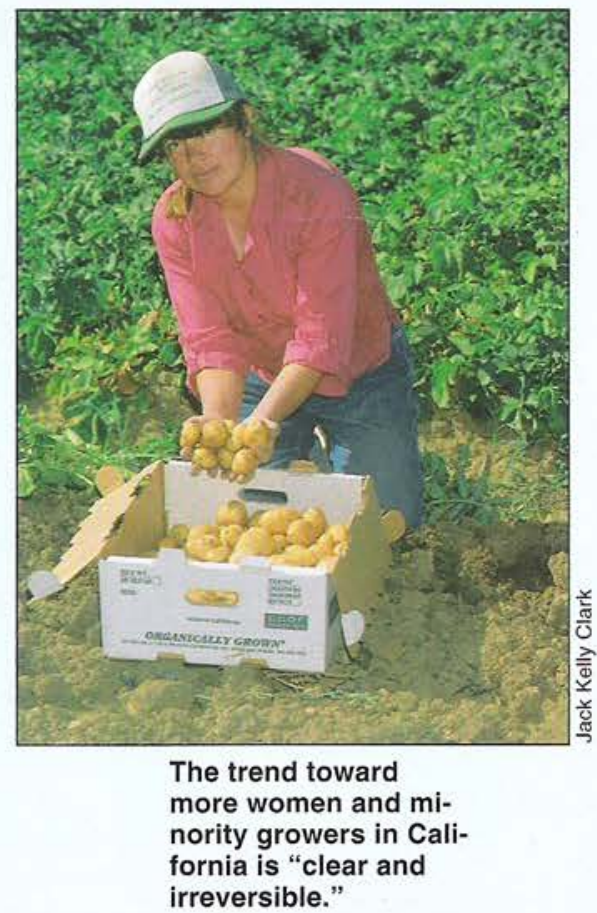

One of the joys of grandparenting is said to be the fun of spoiling the children then sending them home, but an increasing number of children are making their home with their grandparents. According to the 1990 U.S. Census, the percentage of all U.S. children under age 18 living in grandparent-headed households rose from $3.2 \%$ in 1970 to $3.6 \%$ in 1980 and leaped to $4.9 \%$ in 1990 and $5.5 \%$ in 1997 . According to 1997 U.S. Census population surveys, $21 \%$ of these grandparents are over age 65 .

In California, the 1990 U.S. Census recorded 493,080 children living in households headed by their grandparents, comprising $5.4 \%$ of children in the state age 18 and under. If the 1990 prevalence rate of $5.4 \%$ remains constant, projected over the next 25 years, there will be at least 784,000 children living with their grandparents in the state in 2025. With the proportions of both elderly and youth expected to grow in California in the 21st century, this trend is likely to continue if not rise (see pp. 11 and 55).

Alameda County health and nutrition advisor Mary Blackburn set out to determine the distribution of grandparent-headed households among California counties. Blackburn analyzed the 1990 U.S. Census data and found that in San Francisco County, $10 \%$ of children lived with grandparents, the highest rate in the state; the next highest rates were found in Imperial $(8.6 \%)$, Los Angeles $(7.18 \%)$ and Alameda (7.12\%) counties.

"No one has ever looked at the numbers to see how many grandchildren are cared for by their grandparents," Blackburn says.
She hopes UC Cooperative Extension can use these data to develop funding for programs that address the special needs of the children and caretakers in these living arrangements.

"Many grandparents report feeling emotionally, physically and financially devastated by these added responsibilities," says Blackburn, who has worked with groups of grandparents who have assumed parenting roles.

Grandparents are often drafted as caretakers in the event of the parents' death, drug addiction, unemployment, homelessness, incarceration, abandonment, neglect, abuse or lack of child care.

Although these grandparents may be experienced parents and willing to take on the responsibility, they may not be up to the physical demands of the job. In a group of 98 grandparents Blackburn worked with in Alameda County, $81 \%$ reported chronic health problems.

Meredith Minkler, a UC Berkeley public health professor, co-authored a study that found more than $50 \%$ of custodial grandparents had trouble doing heavy housework, $41 \%$ with climbing stairs, $39 \%$ with walking more than six blocks and $17 \%$ with moving about inside the house. For these people, lifting an infant or toddler could exacerbate a physical problem.
In $1997,5.5 \%$ of U.S. children were being raised by their grandparents.

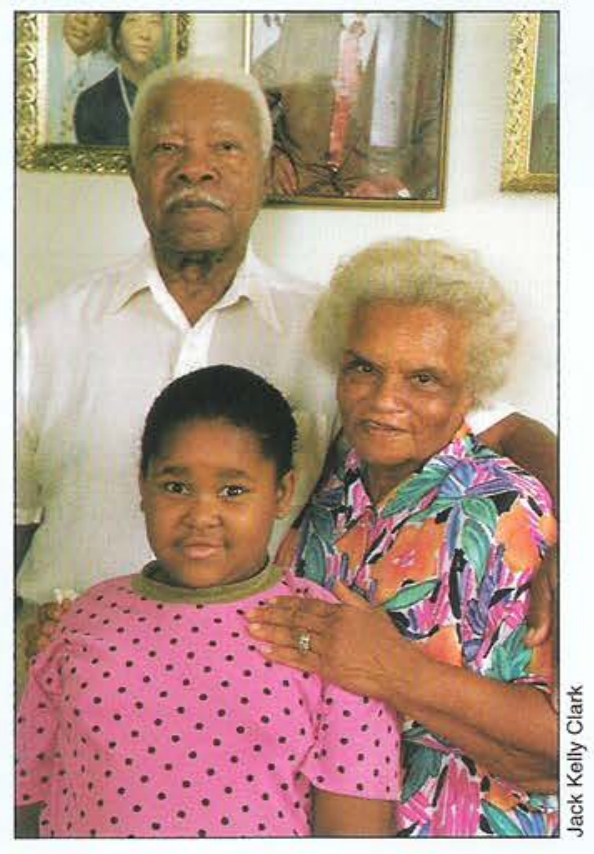


A survey of 121 grandparents at a statewide conference in 1996 showed that $60 \%$ of the children they were tending were under age $10,15 \%$ of the total were 2 years old or younger. The grandparents reported that more than half of the children had physical and emotional problems.

"UC Cooperative Extension specialists and advisors from eight counties are seeking funding to provide grandparents at risk and their grandchildren with education and support services," Blackburn says. "Our goal is to reduce isolation and enhance their nutrition, health and well-being."
Family and consumer science advisors hope to provide grandparents with guidance in parenting, nutrition and family resource and money management.

Blackburn has national and state-by-state data, as well as California data, which have not yet been published. She intends to work with the Alameda County Planning Department again to analyze the 2000 U.S. Census data and compare them to the 1990 prevalence rates. - Pam Kan-Rice

\section{"Tidal Wave II" to hit higher education}

In less than 5 years, the transformation of this field near Merced into the newest UC campus will be well under way.

Gov. Gray Davis has created a "Red Team" to expedite the process in order to begin educating students at UC Merced by 2004.
UC will need to absorb 63,000 additional students during the next decade, nearly $9 \%$ of the projected 700,000 new students expected to enroll in California's public institutions of higher education.

Dubbed "Tidal Wave II" by former UC president Clark Kerr, a major increase in the collegeage population will swell UC's enrollment $43 \%$ between the 1998-99 and 2010-11 school years, to 210,000 students.

This projected increase equals UC's total enrollment growth over the last 30 years, and is equivalent to the existing enrollments of UC Berkeley and UC Los Angeles combined.

"The University is committed to accommodating the students who are headed our way," UC President Richard C. Atkinson said. "We absolutely must keep our promise of access to California's students, and we will do so in ways that maximize efficiency while preserving quality." Under the Master Plan for Higher Education, $\mathrm{UC}$ is obligated to enroll students from the top

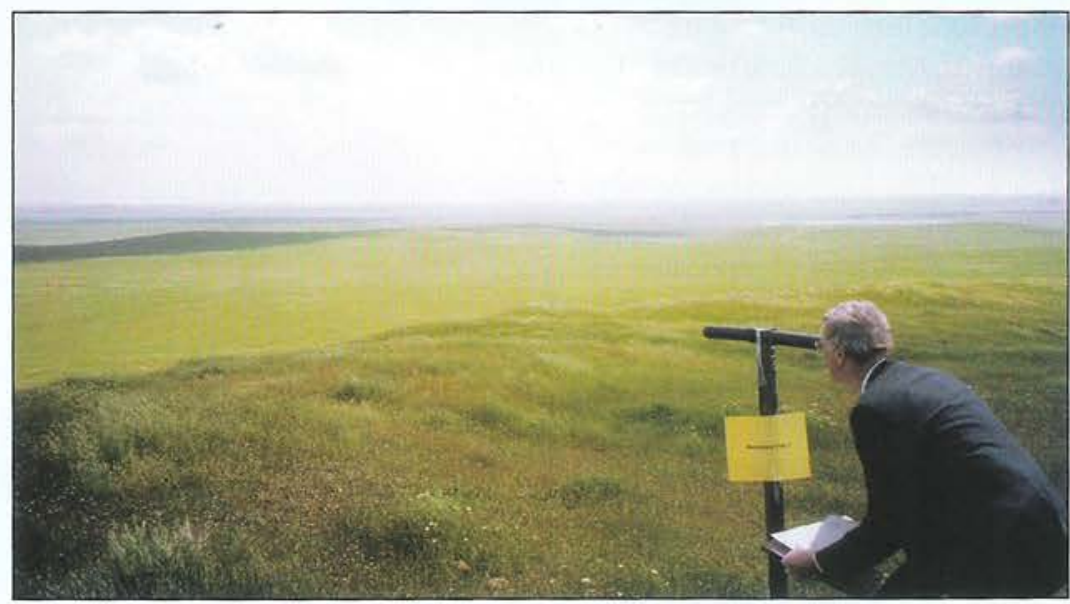

$12.5 \%$ of California's high-school graduating classes each year (see p. 56).

During the 1960s, UC registration also grew sharply as baby boomers enrolled during "Tidal Wave I." But the growth now facing UC is expected to last for a longer period of time, and a smaller proportion will be absorbed by the development of new campuses. The University plans to open one new campus, UC Merced, by 2005 and enroll 5,000 students there by 2010.

Announced Jan. 10, the governor's 2000-01 budget would provide UC with a $12.1 \%, \$ 328$ million increase in general funds, with substantial new funding proposed for the professional development of teachers, faculty and staff salary increases, new investments in research, and 6,000 new students.

To meet enrollment demand, the University is also pursuing a range of strategies such as:

- Increasing instructional activities during the summer.

- Enrolling more students at off-campus locations; the governor's proposed budget would fund a new off-campus center in the Santa Clara Valley.

- Expanding regular enrollments during the fall, winter and spring quarters.

- Shortening students' time to graduation, which currently averages 13 quarters.

Campus growth, along with upgrades of existing facilities, will require $\$ 500$ million per year in capital funding, according to UC Office of the President. The University will need to hire approximately 3,000 new faculty members and expand student services such as housing and advising. 